\title{
The Organization of Chromatic and Spatial Interactions in the Primate Striate Cortex
}

\author{
Daniel Y. Ts'o and Charles D. Gilbert \\ Laboratory of Neurobiology, The Rockefeller University, New York, New York 10021
}

The cytochrome oxidase-rich patches or blobs of the monkey striate cortex have been shown to contain cells that have unoriented receptive fields, many of which are color selective. We studied the functional organization of color opponency in the blob regions of the parafoveal representation of the visual cortex. We also examined the patterns of connectivity among blob and nonblob cells by multiple electrode penetrations and cross-correlation analysis.

Some of the color-selective cells in the blobs exhibited receptive fields that were similar to those found in the parvocellular layers of the lateral geniculate nucleus (LGN): one type exhibited center-surround spatial and chromatic opponency corresponding to the Type I cell found in the LGN; another had center-only chromatic opponency, corresponding to the Type II cell of the LGN. A blob color-selective cell with no LGN counterpart had center color opponency with a nonchromatically opponent surround antagonism. We termed this cell the "modified Type II" cell. Contrary to previous reports, few true double color-opponent cells were found. Some blob cells previously characterized as double opponent probably belong to our modified Type II category and, unlike true double opponent cells, do not respond well to isoluminant color boundaries. Occasional color-selective oriented cells were either intermixed or in close proximity to blob cells.

Neighboring electrode penetrations within the same blob yielded cells of the same color opponency, either red versus green or blue versus yellow, suggesting that individual blobs are dedicated to processing one color opponency. Blobs dedicated to red/green color opponency were 3 times more numerous than blue/yellow blobs. Furthermore, the cells in layer $\mathbf{4 C}$ lying beneath blobs of a given color opponency had identical color opponency to the overlying cells in blobs.

Cross-correlation analysis of pairs of nonblob, oriented cells in the superficial layers showed interactions between cells with matched orientation and eye preference, at varying horizontal separations. Such interactions are consistent with anatomically demonstrated clustered horizontal connections. Positive cross-correlograms were found between blob

Received Apr. 29, 1987; revised Sept. 30, 1987; accepted Oct. 5, 1987.

We gratefully acknowledge the participation of Torsten Wiesel in some of the experiments as well as his invaluable advice and support. We thank Amiram Grinvald and Larry Katz for their comments on the manuscript, Kaare Christian for computer support, Joyce Powzyk for illustrations, Peter Peirce for photography, and Julie Dollinger, Colleen Knowles, and Ann Reardon for histology. The work was supported by NIH grant EY05253 and NSF grants BNS9318794 and BNS8351738, and by an award from the Weill Caulier Trust.

Correspondence should be addressed to Daniel Y. Ts'o, Laboratory of Neurobiology, The Rockefeller University, 1230 York Avenue, New York, NY 10021. Copyright (C) 1988 Society for Neuroscience $0270-6474 / 88 / 051712-16 \$ 02.00 / 0$ cells in the same and in adjacent blobs when the cells' receptive field type, color opponency, and ocular dominance matched. Correlograms also indicated monosynaptic connections from Type II to modified Type II cells of the same color opponency, suggesting that Type II cells may contribute to the construction of the modified Type II fields in the cortex. Finally, correlograms indicated that color-oriented cells receive synaptic input from Type I and modified Type II cells.

Among the most impressive features of the cells of the visual cortex is the specificity of cells for a wide range of receptive field properties, such as orientation, binocularity, direction of stimulus motion, and, in the monkey, selectivity to color. Cells with similar properties were shown to be distributed in columns $(\mathrm{Hu}-$ bel and Wiesel, 1962; Michael, 1981), which seemed appropriate in view of the primarily vertical extent of the connections seen in Golgi studies (e.g., Lorente de No, 1933; Lund and Boothe, 1975). However, subsequent anatomical studies in cat and monkey visual cortex (Fisken et al., 1975; Gilbert and Wiesel, 1979, 1983; Rockland and Lund, 1982; Martin and Whitteridge, 1984; Livingstone and Hubel, 1984b; McGuire et al., 1985) demonstrated the existence of extensive horizontal connections. These long-range horizontal connections exhibit a clustered distribution of axonal collaterals, suggesting a specificity related to the columnar functional architecture. Physiological studies in the cat striate cortex using cross-correlation methods have demonstrated functional connections spanning horizontally between columns of like functional specificity (Ts'o et al., 1986), and the anatomical basis for these interactions may be the clustered horizontal connections.

In addition to the columnar organization of ocular dominance and orientation preference, the development and use of a staining procedure for cytochrome oxidase revealed another major organizational feature of primate striate cortex: the cytochrome oxidase-rich patches or blobs (Wong-Riley, 1979; Horton and Hubel, 1981; Humphrey and Hendrickson, 1983). Interspersed in the regular columns or bands of orientation and ocular dominance was found a matrix of blobs, patches of high cytochrome oxidase activity, containing cells that were unoriented, monocular, and often color selective (Livingstone and Hubel, 1984a). In addition to several blob cell types that exhibited receptive field properties similar to LGN cells (Wiesel and Hubel, 1966), Livingstone and Hubel (1984a) reported large proportions of cells with a double color-opponent receptive field, a functional property that, like orientation, binocularity, and directionality, is probably constructed via intrinsic connections in the cortex. Livingstone and Hubel (1984b) then explored relationships between the blobs and horizontal connectivity. Using focal extra- 
cellular injections of HRP, they found a segregation of horizontal connections between the blob regions and the nonblob regions.

In the present study, we examined the specificity and character of connections in the monkey striate cortex, focusing on the local and the longer range horizontal connections among blob cells, as well as the oriented cells of the interblob regions. In studying the interactions and connections among these cells, we found it necessary to re-examine and characterize the properties and organization of blob cells (see Part I). We then used the cross-correlation technique in combination with receptive field analysis to probe the functional role of the connections among the blob cells and the nonblob (interblob) cells (see Part II).

\section{Materials and Methods}

Adult monkeys (Macaca fascicularis) were initially anesthetized with ketamine $\mathrm{HCl}(20 \mathrm{mg} / \mathrm{kg}$, I.M.) followed by sodium pentothal $(20 \mathrm{mg} /$ $\mathrm{kg}$, I.V., supplemented by further injections as needed). The electrocardiogram, electroencephalogram, temperature, and expired $\mathrm{CO}_{2}$ were monitored. The animal was then cannulated through a tracheotomy, paralyzed with vecuronium bromide $(0.1 \mathrm{mg} / \mathrm{kg} / \mathrm{hr})$, and artificially respirated. The EEG was monitored and sodium pentothal was given I.P. continuously at a rate to assure that the animal was asleep $(1-3 \mathrm{mg} / \mathrm{kg}$ / $\mathrm{hr}$ ). The pupils were dilated with $1 \%$ atropine. A retinoscope was used to determine the appropriate contact lenses to focus the eyes on a tangent screen $1.5 \mathrm{~m}$. from the animal. The positions of the fovea of cach cyc were plotted on the screen with the aid of a fundus camera (Nikon).

A hole above the striate cortex about $3 \mathrm{~mm}$ in diameter was made in the skull $15 \mathrm{~mm}$ anterior to the occipital ridge and $10 \mathrm{~mm}$ lateral to the midline. After the dura was opened, the surface of the cortex and vasculature was photographed to provide a reference for electrode placement and subsequent histological reconstruction. One or two tungsten wire electrodes (Hubel, 1957) were placed perpendicular to the cortical surface and positioned for vertical penetration; the hole was filled with agar to reduce pulsations.

Each electrode was advanced with a microstepper motor (Ardel-Kinematic). The receptive field position and properties of encountered single units were studied with slits of light from a hand-held projector. The orientation preference, directionality, ocular dominance, receptive field size and position, cxtent of cnd inhibition, cdge preference, and response to stationary light flashes were determined for each unit. The receptive field positions of the cells were generally $3^{\circ}-7^{\circ}$ from the fovea. Cells were classified into ocular dominance groups 1-7 according to Hubel and Wiesel (1962). Orientation tuning sharpness was ranked on a 4-point subjective scale ranging from very sharp, A (subjective full width of $\pm 15^{\circ}$ ), to $\mathrm{D}$ (no detectable orientation tuning) (Livingstone and Hubel, 1984a).

The tangent screen was illuminated with a constant white background of $2 \mathrm{~cd} / \mathrm{m}^{2}$. Colored Wratten filters (Kodak, red 29, green 61, yellow 15 , blue 47 ) placed in front of the hand-held projector provided an initial assessment of any color specificity in a cell's response. Further color and spatial analysis used a computer-controlled color video stimulator (Adage/Ikonas), which also presented light stimuli for response histograms and correlograms. A color raster CRT monitor (Tektronix $690 \mathrm{SR}$ ) displayed the output from the stimulator. The luminance of the CRT stimuli was usually $100 \mathrm{~cd} / \mathrm{m}^{2}$. Simultaneous and successive color contrast was presented at approximate isoluminance, although a range of intensities was explored.

The 2 extracellularly recorded signals were amplified and fed into 2 window discriminators that provided digital pulse outputs. The threshold levels of the window discriminators were constantly monitored for proper triggering to a single unit. The 2 digital pulse outputs were processed in real time by a microprocessor (DEC PDP11/73) to provide on-line computation and display of stimulus histograms, autocorrelograms and cross-correlograms. Correlograms were computed and interpreted as described by Ts'o et al. (1986), including the use of shuffing to remove any stimulus coordination artifact, a normalization with respect to baseline correlation. For correlograms with a pcak indicating a monosynaptic interaction, the contribution was computed (Levick et al., 1972) as the percentage of spikes occurring in the driven cell that also accumulated in the peak (minus the baseline correlation).

Electrolytic lesions were made to mark positions along the penetra-

\begin{tabular}{lcccccccc}
\hline Table 1. & A sample of $\mathbf{4 7 4}$ blob cells & & & \\
Type & I+ & I- & II & mod II & III + & III - IV & DO \\
\hline Red & 45 & 8 & 33 & 56 & & & & 2 \\
Green & 7 & 2 & 10 & 14 & & & & 1 \\
& & & & & 120 & 36 & 26 & \\
Blue & 16 & 3 & 19 & 31 & & & & 0 \\
Yellow & 10 & 2 & 11 & 20 & & & 2 \\
Totals & 93 & 73 & 121 & 156 & 26 & 5 \\
& $(20 \%)$ & $(15 \%)$ & $(26 \%)$ & $(33 \%)$ & $(5 \%)$ & $(1 \%)$
\end{tabular}

The distribution of 474 blob cells, classified by receptive field type, center color, and center sign, On $(+)$ or Off $(-)$. DO, double color opponent: mod II, modified Type II (see text for a description of field types). For Type I cells, the listed color refers to the center color. For Type II, modified Type II, and double color-opponent cells, the listed color refers to the center color that elicited an On response. Cells with a given center color and sign gave responses of the opposite sign to the opponent color (e.g., a Type I red On-center cell had a green Off-surround, a blue On-center Type II cell, gave an Off response to a yeliow center spot).

tions for later histological reconstruction. Lesions of approximately 100 $\mu \mathrm{m}$ in diameter were made by passing $3 \mu \mathrm{A}$ of current through the electrode for $3 \mathrm{sec}$. After the experiment was finished, the animal was perfused with $4 \%$ formaldehyde. Blocks of tissue containing the electrode tracks were sectioned on a freezing microtome (American Optical Co.) to $30 \mu \mathrm{m}$ thickness. These sections were mounted on gelatinized slides and stained for cytochrome oxidase with the procedure of WongRiley (1979). The lesions and surrounding cytochrome oxidase-rich blobs were reconstructed using a camera lucida-equipped microscope (Zeiss).

\section{Results}

\section{Part I: Receptive field properties and organization of blob} cells

The aim of our initial set of experiments was to study the response properties of cells found in the cytochrome oxidase-rich blob regions. We made multiple vertical penetrations of a single electrode in the superficial layers of striate cortex to locate regions of cells with unoriented receptive fields. Subsequent histological reconstructions of electrode tracks and lesions in sections stained for cytochrome oxidase were matched with our recording protocols to confirm penetrations that were in blob regions. Cells in blobs had receptive fields that were poorly oriented or completely unoriented (class C or D of Livingstone and Hubel, 1984a) and were strongly monocular (groups 1, 2, 6 , or 7). The spatial organization and color selectivity of the receptive fields of blob cells could be divided into categories or types, most of which rescmbled those found in the lateral geniculate nucleus (LGN) (Wiesel and Hubel, 1966). We recorded from a total of 474 blob cells. The various types of cells found are detailed below, and an enumeration of the cells found in each catagory is given in Table 1.

One class of receptive field was similar to the Type I LGN cell. These cells had an opponent color center-surround organization and responded best, either On or Or, to a center spot of a particular color. Small white spots also stimulated the cell well. A large spot of the optimal color gave a response of the same magnitude as a small spot. However, larger spots of white or other colors did not excite the cell and usually suppressed the spontaneous firing completely. Using a color annulus of the color opponent to the center color (e.g., a green annulus for a red center cell, or a blue annulus for a yellow center cell), a response of the opposite sign was often elicited from the surround (e.g., red On-center with green Off-surround). Examples of both red/green and blue/yellow Type I cells in both On-center 
Figure 1. Poststimulus time histograms from a red-On green-Off standard Type II blob cell. Responses summed from 50 trials of $1 \mathrm{sec}$ flashes of small $\left(1^{\circ}\right)$ and large $\left(10^{\circ}\right)$ spots of red and green light. Integrated responses to large red and green spots were 18 and $13 \%$ greater than to corresponding small spots. The center size of the receptive field was $34^{\circ}$. Vertical scale, 100 spikes/ bin; bin size, $25 \mathrm{msec}$.
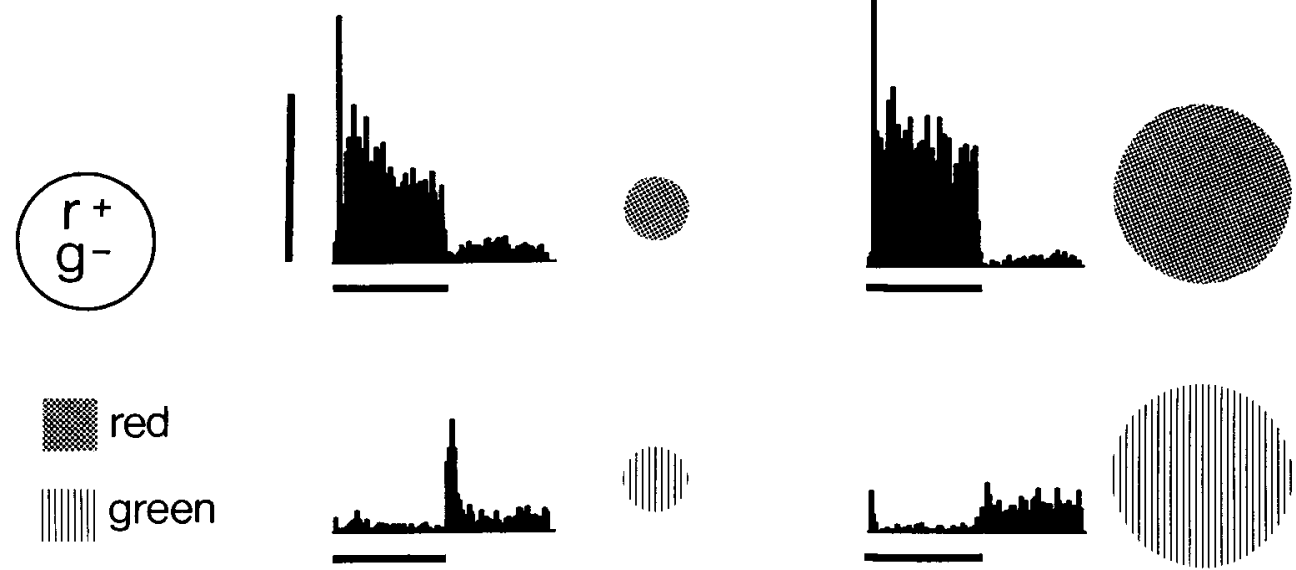
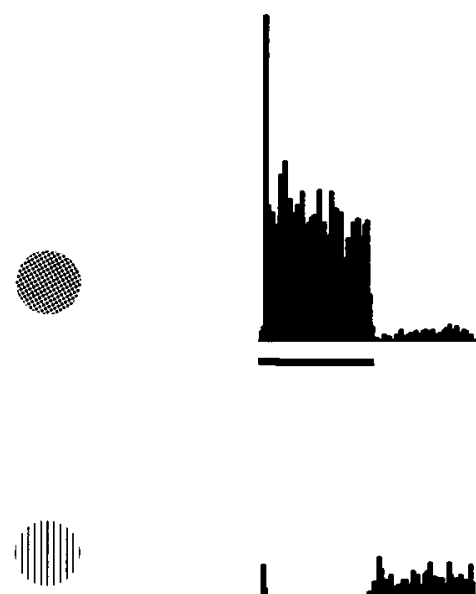
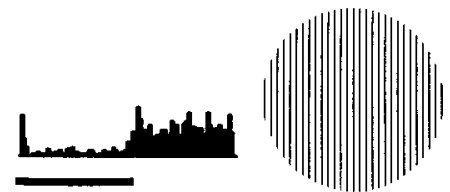

and Off-center varieties were found. From a sample of $474 \mathrm{blob}$ cells, $17 \%$ were Type I On-center and $3 \%$ were Type I Off-center (see Table 1).

A second class of blob cells corresponded to another type of cell found in the LGN, the Type III cell. These cells had either On or Off centers and antagonistic surrounds but no color opponency. Small center spots of white, red, green, or yellow produced strong responses, while larger spots evoked no response, often suppressing the spontaneous firing entirely. This response type has also been termed broadband center-surround (Livingstone and Hubel, 1984a). We noted that most, but not all, Type III cells did not respond well to small center spots of blue light of even high intensity. On-center Type III cells accounted for $25 \%$ of our sample, and Off-center Type III cells represented $8 \%$.
A curious class of cells found in the ventral layers of the monkey LGN was categorized by Wiesel and Hubel (1966) as Type IV. These LGN cells were similar to the Type III cells in their broadband center and antagonistic surround responses. However, Type IV cells exhibited a characteristically rhythmic pattern of firing, high spontaneous activity, and large spots of red light produced a dominant and long-lasting suppression. We categorized a class of blob cells as Type IV because of certain similarities to their LGN counterparts. These blob cells also had a characteristic and rhythmic spontaneous activity and broadband center-surround responses. However, large red spots often produced an excitatory dominating sustained response instead of the inhibitory response found in LGN type IV cells. The Type IV cells represented $5 \%$ of our sample.

Another class of blob cells exhibited color opponency but did
Figure 2. Response histograms summed from 50 trials of a red-On green-Off modified Type II blob cell. Tests of $1 \mathrm{sec}$ flashes of small $\left(1^{\circ}\right)$ and large $\left(10^{\circ}\right)$ spots of red and green, as well as colored annuli with $10^{\circ}$ outer diameter and $2^{\circ}$ inner diameter and a combined red center, green surround stimuli of the same dimensions. Integrated responses to the large red and green spots were $67 \%$ less than to the corresponding small spots and the response to the red/green color contrast stimuli was $59 \%$ less than to the small red spot alone. The center size of the receptive field was $12^{\circ}$. Vertical scale, 100 spikes/bin; bin size, $25 \mathrm{msec}$.
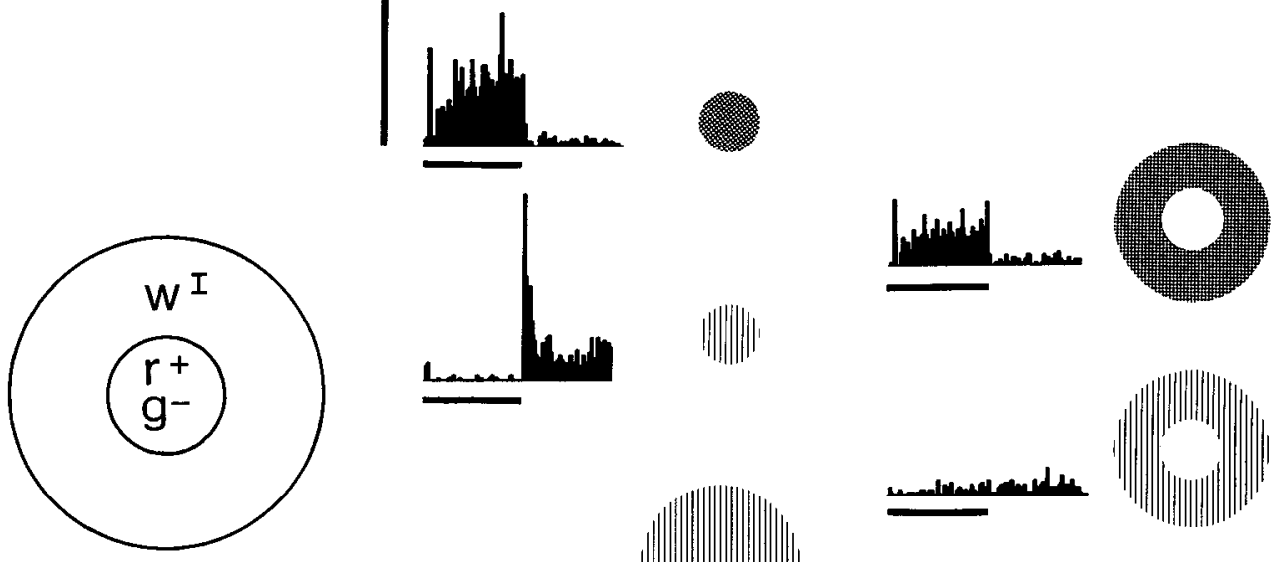

red

green
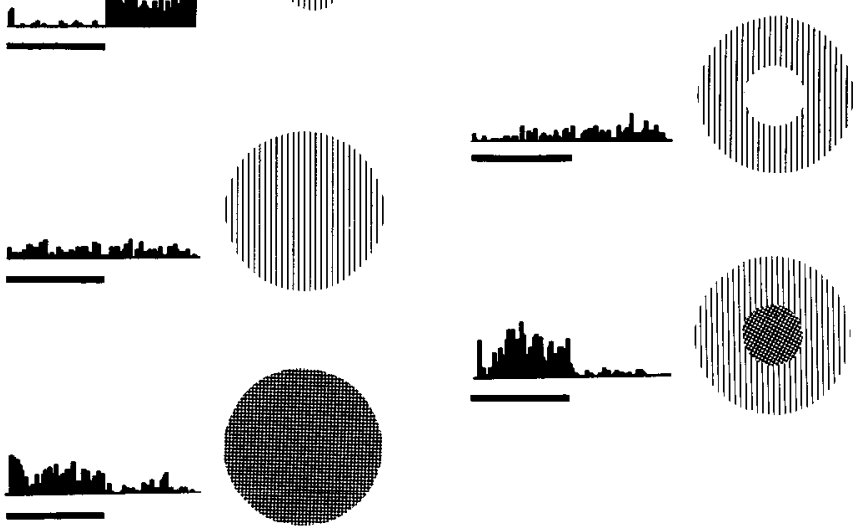
not have a center-surround organization. These cells, like Type II LGN cells, had On responses to a particular color and Off responses to the opponent color. Of our sample of 474 blob cells, 15\% were classified as Type II cells. Figure 1 shows the response of a typical standard red-On green-Off Type II blob cell to small and large spots of red and green. Brisk On and Off responses were maintained over increasing spot sizes for the appropriate color and thus had no surround suppression. As shown in Figure 1, the responses to large red and green spots were at least as large as the responses to small spots of the same color. Type II cells did not respond well, if at all, to any size spot of white light. Both red/green and blue/yellow Type II cells were found.

An intriguing type of blob cell with no counterpart in the LGN had center-surround spatial opponency and color opponency in the center. Small spots of colored light produced responses similar to those of a Type II cell, i.e., a particular color elicited an On response, while its opponent color gave an Off response. Unlike the Type II cells, however, increasing the spot size diminished the center response (Fig. 2). In this example, the response decreased by $67 \%$ when a large red or green spot was presented, relative to the small spot responses. We termed these cells "modified Type II." They represented $26 \%$ of our sample.

To test whether this surround suppression represented a double color-opponent organization, we further tested such cells with colored annuli. A white annulus and annuli of all colors suppressed the center response, and we were unable to reverse the sign of the center response when that same color was only presented in the surround. For example, in Figure 2 for a red On-center, green Off-center modified Type II cell, the response to a red annulus was still On, instead of Off, and the response to a green annulus was also unchanged in sign, as would be expected for a true double color-opponent cell. Furthermore, the green surround response was not converted from Off to On even with the presence of a red biasing spot in the center. In addition, the response of a double-opponent cell to color contrast, such as a red center, green surround stimulus should be vigorous, at least as large as the red center spot alone. Yet this cell's response to such a stimulus was diminished compared with the red center spot (by 59\%). As annuli of all colors suppressed the center On and Off responses to a similar degree, we could find no color selectivity of the surround antagonism.

In addition to cells showing red/green opponency, we also cncountcred cells with blue/yellow opponency. Figure 3 shows the responses of a blue-On yellow-Off Type II cell found in a blob. The cell's response to red or green spots was negligible. A yellow-On blue-Off modified Type II cell is shown in Figure 4. Note again that its responses to annuli of a given color were not of the reverse sign of the center response of the same color and that its response to the yellow/blue spatial color contrast was poor. To test the possibility that blue excitatory input to the cell in the surround was actually present but subthreshold, we tried to elicit a blue-On surround response by biasing the excitation of the cell with a stationary small yellow spot in its field center. However, a flashing blue annulus under these conditions did not yield an On response, as would be expected for a double color-opponent field.

There were a few ( 5 of $474,1 \%$ ) blob cells that could be classified as true double color opponent, as the annulus response to a given color was reversed in sign to the center response of the same color. Of these double color-opponent cells, 2 were
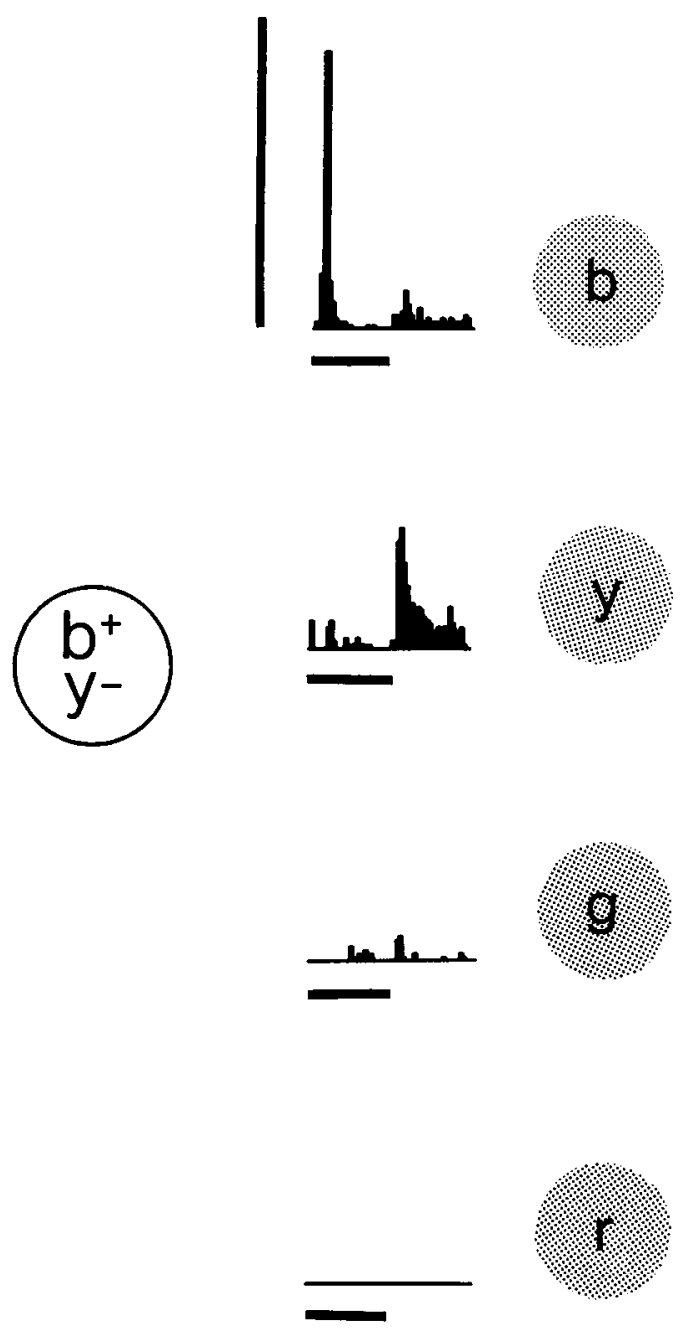

Figure 3. Blue-On yellow-Off standard Type II blob cell. Responses summed from 50 trials. Spot size, $1^{\circ}$; time bar, $1 \mathrm{sec}$ flashes; verticai scale, 100 spikes/bin; bin size, $25 \mathrm{msec}$.

red-On green-Off center, 1 was green-On red-Off center, and 2 were yellow-On blue-Off center.

Some blob cells (Type I, modified Type II, and Type III) were extremely sensitive to the movement of stimuli, showing 1000 fold increases in their responses to moving spots over stationary flashing spots, regardless of direction. A few blob cells demonstrated a color selectivity that was difficult to place into the above categories.

Although we did not systematically search for color-selective oriented cells, 16 red-, 11 green-, 4 yellow-, and 2 blue-selective oriented complex cells were found in our sample, all close to or intermixed with unoriented blob cells of like color specificity. These cells responded poorly to white bars and edges and vigorously to bars of the optimal color, regardless of intensity. Their orientation selectivity was sharp to moderately sharp (class A or B of Livingstone and Hubel, 1984a; see Materials and Methods).

Functional architecture of color opponency. An important feature of the distribution of cells in the blobs was that cells of the same color opponency were clustered. In both individual vertical electrode penetrations and in groups of neighboring penetrations within the same blob, the color-selective cells were of 

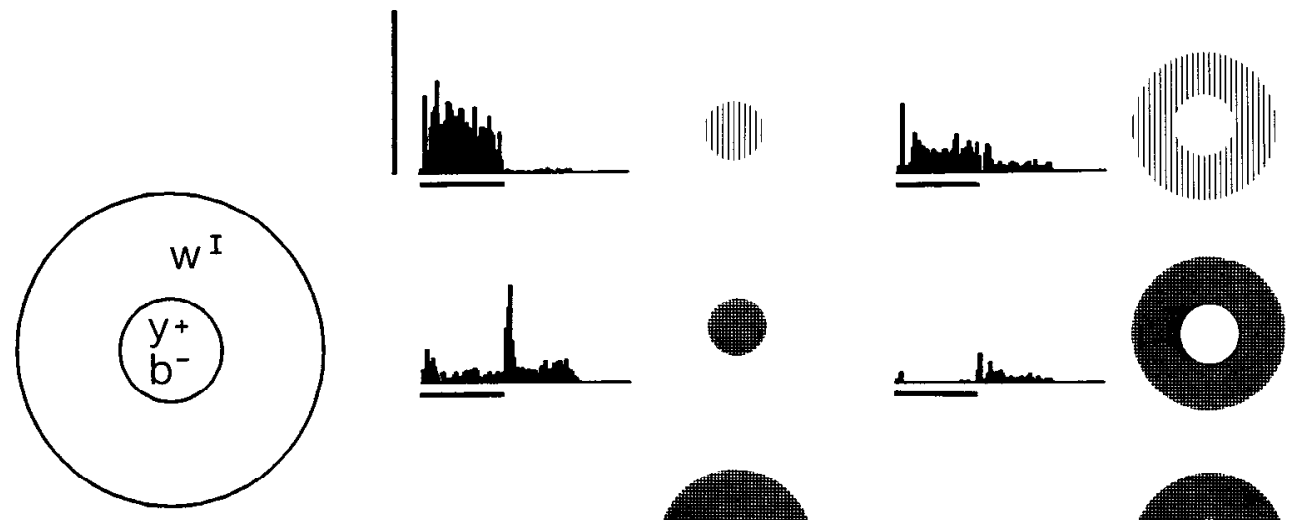

Figure 4. Response histograms summed from 50 trials of a yellow-On blue-Off modified Type II blob cell. The striped pattern at the bottom right indicates a stationary yellow center spot with a flashing blue surround stimulus. Sizes of spots and annuli as in Figure 2 . The center size of the receptive field was $1 / 2^{\circ}$. Time bar, 1 sec flashes; vertical scale, 100 spikes/bin; bin size, $25 \mathrm{msec}$.

the same opponency, either blue/yellow or red/green (Figs. 5-7). Several example penetrations are shown in Figure $7 A$. These findings led us to speculate that large portions, or perhaps the entirety, of a single blob were devoted to one color-opponency system. It should be noted that between the clusters of blob cclls of like color opponency, there were Type III broadband cells, both in penetrations with red/green and blue/yellow color opponent cells. There was also the tendency for blob cells to be clustered according to receptive field type, I, II, modified II, III, or IV, as well as color opponency of the same sign, e.g., blueOn yellow-Off, rather than blue-Off yellow-On (Figs. 5 and 6).

To further test the idea that blobs are dedicated to one color opponency, we made systematic maps of portions of cortex in and around single blobs with closely spaced multiple penetrations (Fig. $7 B$ ). We began by locating a blob, determining the color opponency represented, and then completely surrounded the blob with penetrations until we found transitions between the blob and the oriented interblob regions. Each penetration sampled properties of cells every $50 \mu \mathrm{m}$ from the surface of the cortex to layer 4B. In Figures 7 and 8, colored dots on the map represent the On color of the response of color-selective cells found at that recording site. Thus, a red dot indicates that redOn, green-Off cells were found (see figure legends for further details). A shift in center color sign (e.g., red-On to red-Off) was rarely seen in an individual penetration, occurring only twice in 125 blob penetrations. In the example shown in Figure $7 B$, only red/green color opponency was found. It is interesting to note that color-oriented cells, usually with color selectivity related to the blob cells, were sometimes found near the nonoriented blob cells, at times even in the same vertical penetration (Fig. $7 B$ ). Figure $7 C$ shows an example where the same strategy was used for a blue/yellow blob. Only blue/yellow cells were found. We repeated this strategy for $8 \mathrm{red} / \mathrm{green}$ blobs and 8 blue/yellow blobs. No intermixing of color opponency was found in this sample. These findings suggest that individual blobs are color-opponency specific. However, for a given color opponency different parts of a given blob contained cells with either center color and/or sign. A possibility that we have not ruled out is whether certain blobs contain only Type III broadband cells. An example of a series of penetrations that suggest this possibility is shown in Figure $7 A$, where 5 adjacent penetrations only yielded Type III cells.

We next asked if the red/green and blue/yellow blobs were evenly or randomly distributed and what their relative abundance was. As shown in Figure 8, top, we mapped a larger area of cortex, focusing not on studying individual blobs thoroughly but establishing the color opponency represented in a number of blobs. Together with the cytochrome oxidase histochemistry from the same experiment, we reconstructed the layout of the red/green and blue/yellow blobs (Fig. 8, bottom). No general rule governing the layout of red/green and blue/yellow blobs such as a simple alternation or checkerboard was apparent.

Of the 146 blob regions we recorded from, we determined 109 to be red/green and 37 to blue/yellow, a $75 \%$ red/green, $25 \%$ blue/yellow color opponency representation. These percentages probably better reflect the relative portion of cells in the 2 color-opponency systems than would an estimate based on our sample of cell numbers. Of our sample of color-selective blob cells, $61 \%$ exhibited red/green opponency, whilc $39 \%$ showed blue/yellow opponency. However, our experimental strategy may have biased these percentages in favor of finding blue/yellow cells, since we made more penetrations in the blue/ yellow blobs searching for red/green cells.

Anatomical evidence suggests that layer $4 \mathrm{C}$ projects to the superficial layers (Lund and Boothe, 1975; Fitzpatrick et al., 1985) and may contribute input to the blob cells in those layers (Michael, 1986). Thus, we were curious as to the color specificity of the layer $4 \mathrm{C}$ cells underlying blobs of known color specificity. We made extended vertical penetrations, first entering a blob and determining the color opponency represented, and then advancing to layer $4 \mathrm{C}$ and determining the color opponency of cells in that layer. Figures 5 and 6 show examples of such penetrations. In penetrations in 6 different red/green blobs, all underlying layer $4 \mathrm{C}$ cells that were color opponent were also red/ green. Layer $4 \mathrm{C}$ cells were also blue/yellow in penetrations in 7 different blue/yellow blobs. In viewing these figures, the pen- 


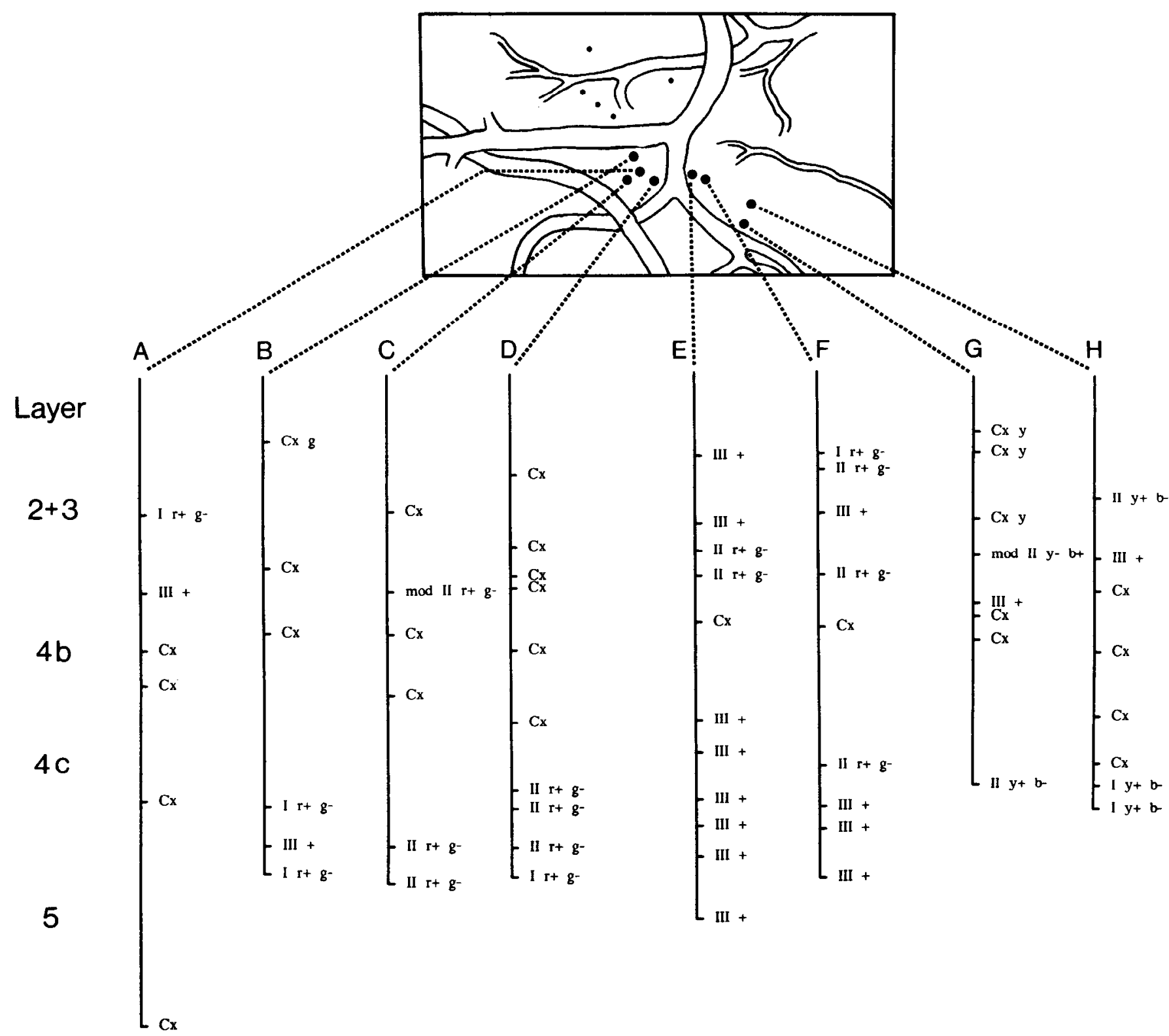

Figure 5. Electrode penetrations in blob regions, extending to layer $4 \mathrm{C}$ and corresponding surface maps. Smaller black dots on surface maps indicate positions of other electrode penetrations not detailed. Approximate cortical layer shown on left derived from histological reconstruction of electrolytic lesions. Adjacent to each penetration record, the types of cells found are indicated: $C x$, complex oriented; mod $I I$, modified Type II. For Type I cells, the first color ( $r$, red; $g$, green; $b$, blue; $y$, yellow) indicates the center color and the second color, the surround color. Penetrations $A-F$ were through or near blob regions containing cells of red/green color opponency, with like color opponency found in layer $4 \mathrm{C}$. An adjacent blob region $(G, H)$ had cells with blue/yellow color opponency in layers $2+3$ and $4 \mathrm{C}$. Note the region of complex cells in layer $4 \mathrm{~B}$.

etrations in a given blob should be considered together in determining the relationship between the color opponency of the superficial layer blob cells and the underlying $4 \mathrm{C}$ cells, even though certain individual penetrations strayed into neighboring interblob regions containing non-color-selective complex cells.

In contrast to these 13 examples in which the color opponency of the superficial layer blob cells matched that of the layer $4 \mathrm{C}$ cells, there were 3 single penetrations in which the color opponency above did not match that of cells in layer $4 \mathrm{C}$. It is possible that these exceptions represent penetrations that were not adequately vertical. In 4 penetrations in which the blob cells above were broadband Type III cells, the corresponding layer $4 \mathrm{C}$ cells were also broadband Type III. Penetrations into a red/ green blob and an adjacent blue/yellow blob are shown in Figure
5. A penetration into a blue/yellow blob in Figure 6 (left) illustrates one of the few exceptions, where some red/green cells were found in layer $4 \mathrm{C}$. We often found a cluster of complex, oriented cells in layer 4B (Figs. 5 and 6); frequently these were strongly direction selective. In a few penetrations (e.g., Fig. 6, right), however, we encountered unoriented, monocular, colorselective cells throughout layer 4 . Although we did not study the cells in layer 4B extensively, we found unexpectedly few simple cells, in view of the results of Livingstone and Hubel (1984a) and Michael (1985).

Another notable observation from our study of blob regions was the occasional occurrence of what appeared to be bridges of unoriented, color-selective cells in between 2 blob regions. These bridges of bloblike cells could occur either along an ocular 

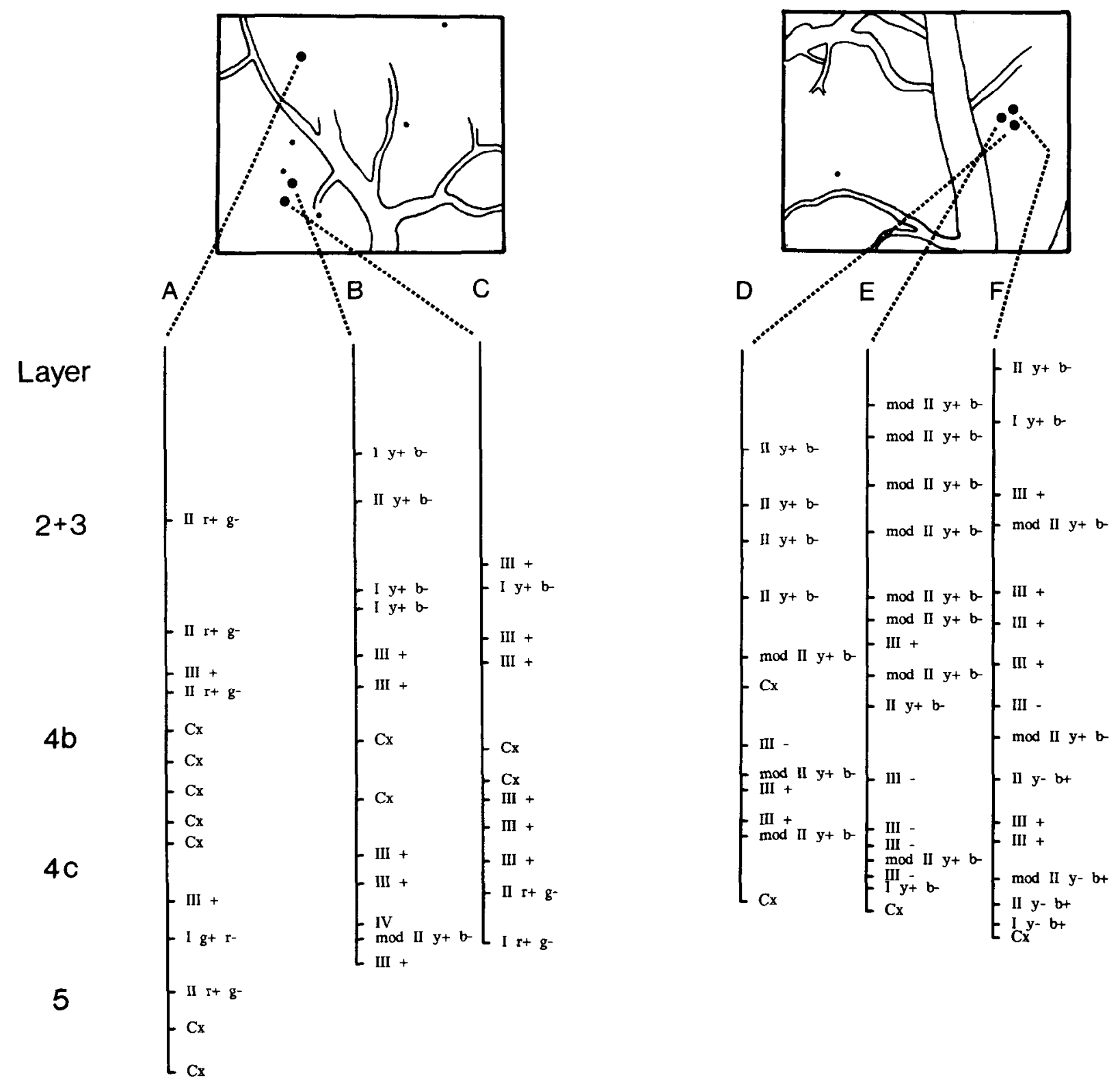

Figure 6. Electrode penetrations in blob regions, extending to layer $4 \mathrm{C}$ (markings as in Fig. 5). Penetrations $B-F$ were through blob regions containing only cells of blue/yellow color opponency. Underlying cells in layer $4 \mathrm{C}$ also showed blue/yellow color opponency, except for penetration $C$. Note penetrations $E$ and $F$, which did not find complex cells in layer $4 \mathrm{~B}$.

dominance column or, surprisingly, between 2 blob regions of different ocular dominance. While it was sometimes difficult to know whether the presence of unoriented, bloblike cells was absolutely continuous between 2 blobs, such findings suggest the occasional joining of neighboring blob regions. Closc cxamination of tangential sections stained for cytochrome oxidase (Fig. 9) also revealed the occurrence of seemingly joined blobs, as well as bridgelike densities of staining running between blobs (Horton, 1984). It is possible that the few unoriented, bloblike cells we recorded that were binocular (groups 3-5) were located in these bridgelike regions between blobs.

\section{Part II: Connectivity of blob and nonblob cells}

In addition to the issues of color opponency and organization examined in Part I, we were interested in the neuronal circuitry underlying the various receptive field types found in the blobs and in the interblob regions. Using extracellular injections of HRP, Livingstone and Hubel (1984b) found that connections between neighboring blobs were segregated from those between interblob regions: blob cells were shown to transport label to cells in neighboring blobs, skipping interblob regions. Likewise, interblob regions were shown only to transport to other interblob regions, not to blobs. We have explored the functional significance of these connections by combining the cross-correlation technique with receptive field analysis.

Our general strategy in the cross-correlation analysis was to record from pairs of electrodes spaced from $50 \mu \mathrm{m}$ to $1 \mathrm{~mm}$ apart in the superficial layers, and to isolate single units in each recording channel. This enabled us to correlate the firing between cells with various combinations of receptive field types, 


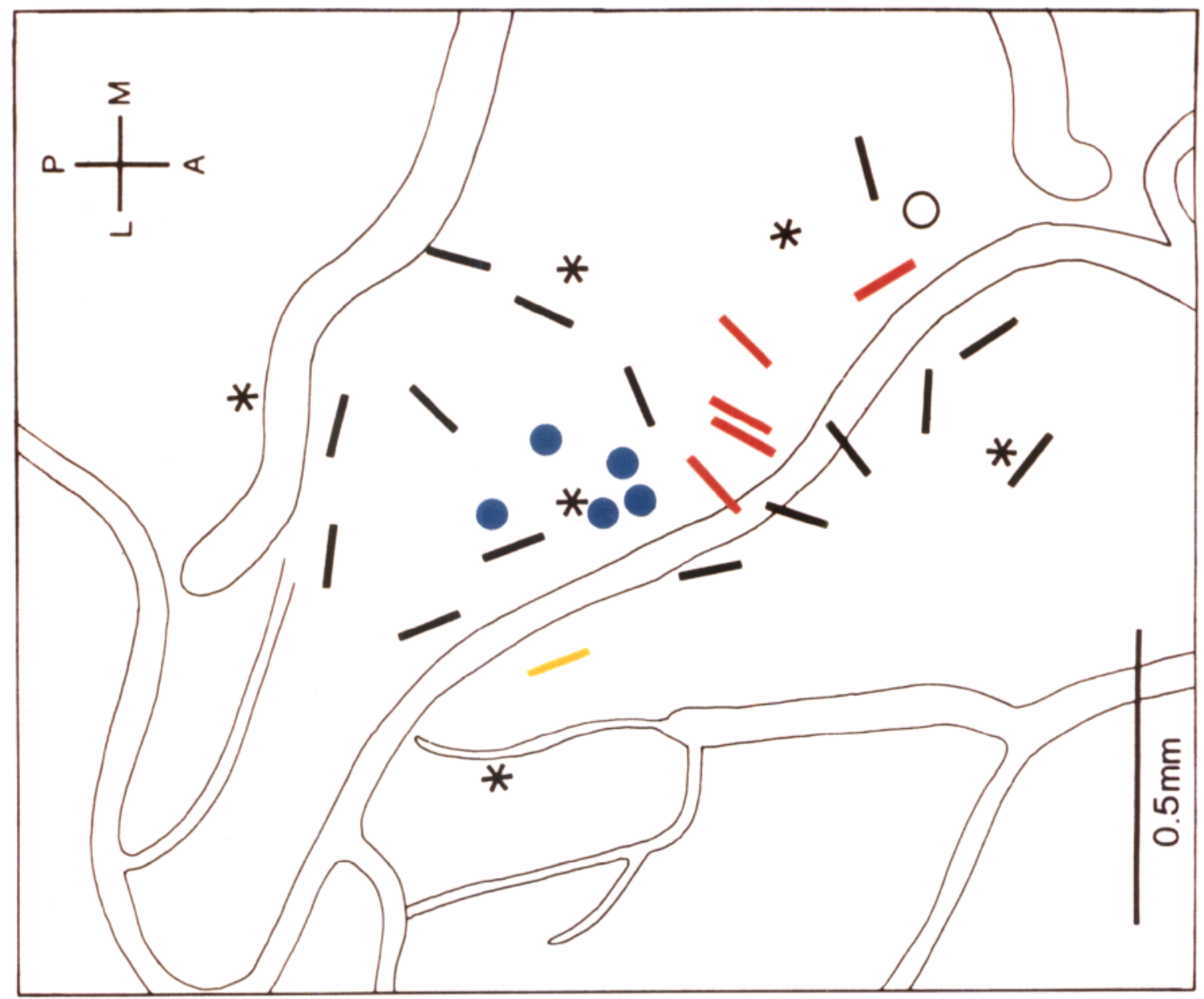

U
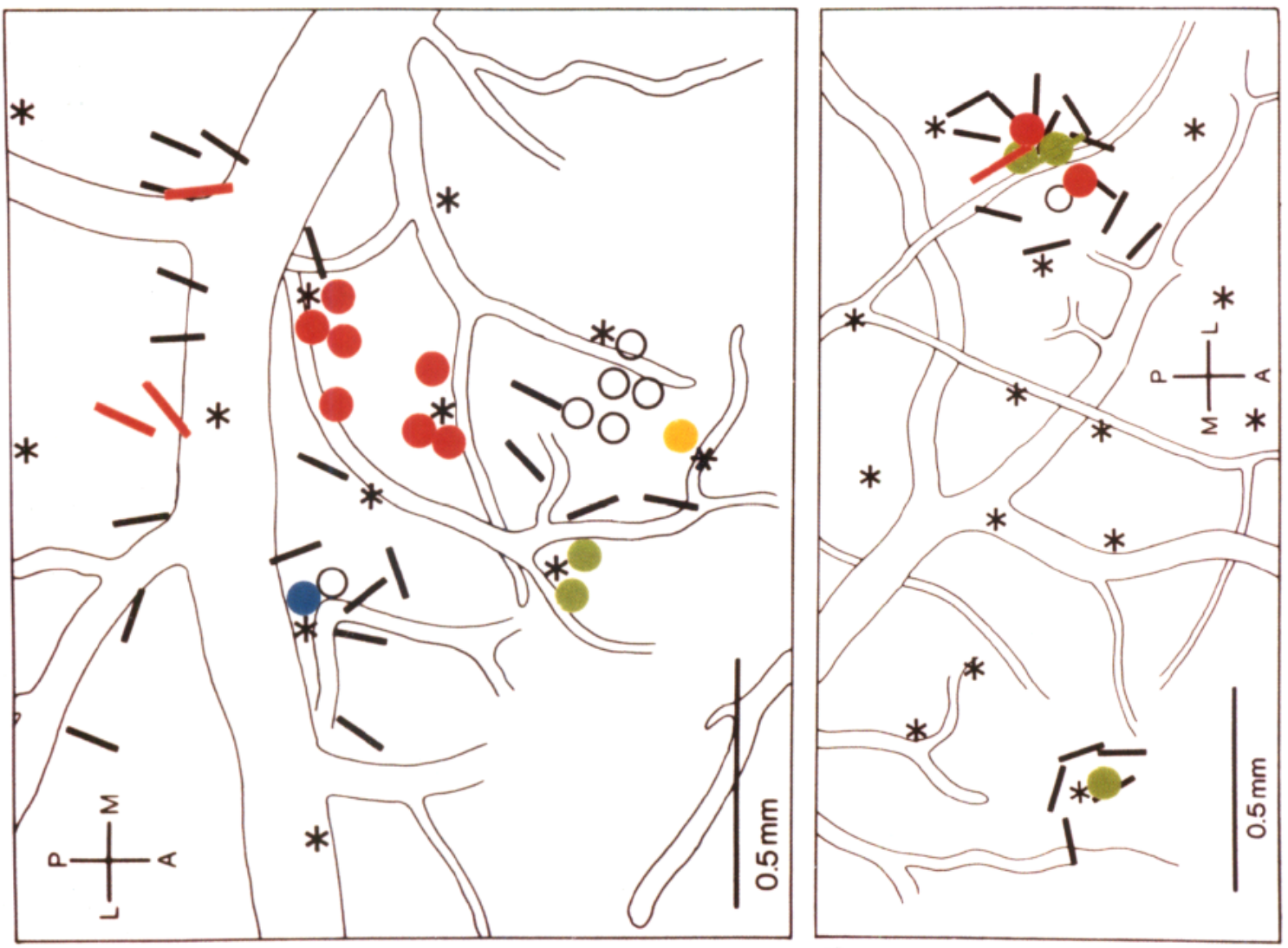

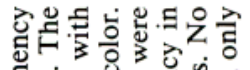

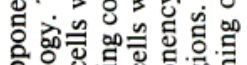

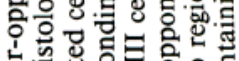

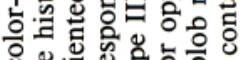

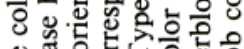

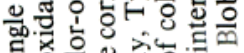

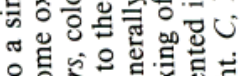

ช

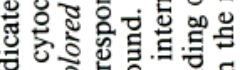

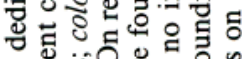

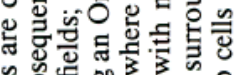

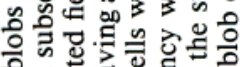

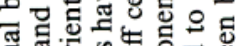

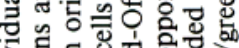

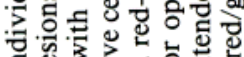

늘

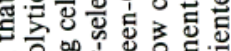

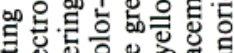

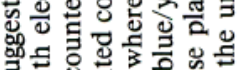

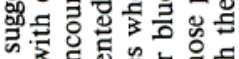

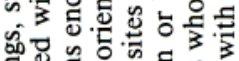

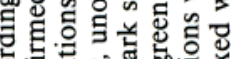

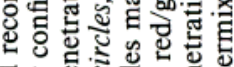

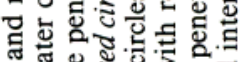

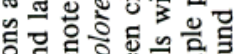

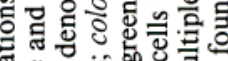

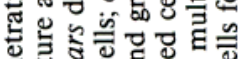

氜氜氜

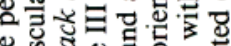

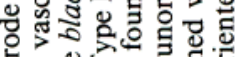

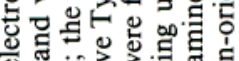

的昰范

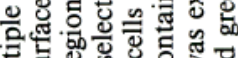

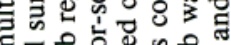

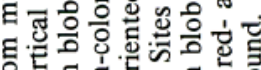

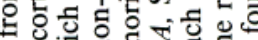

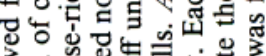

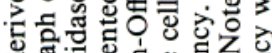

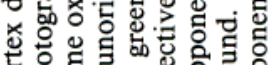

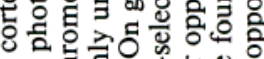

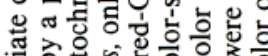

D东包 800

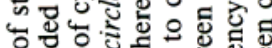

萌

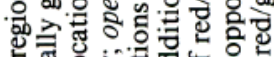

๙

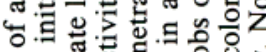

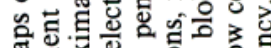

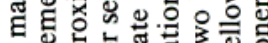

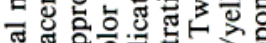

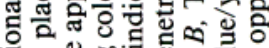

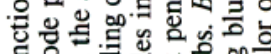

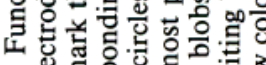

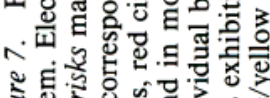

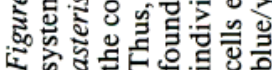




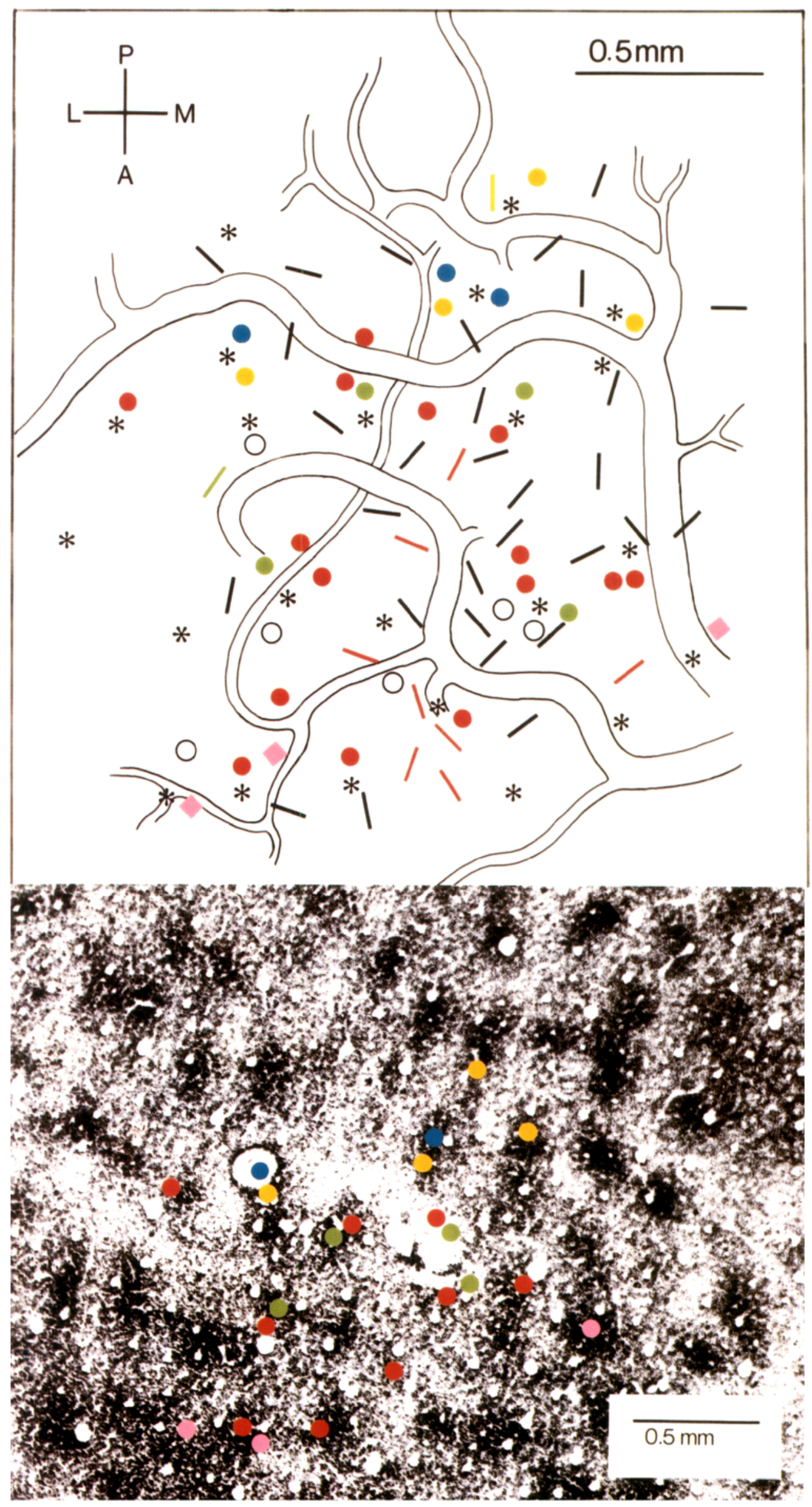

Figure 8. Top, Functional map of a larger region of striate cortex examining the distribution of red/green and blue/ yellow blobs. Pink symbols mark sites where Type IV cells were found. Bottom, Cytochrome oxidase histology from the same experiment. Colored dots over blob regions do not correspond to specific electrode penetrations but serve to indicate the color opponency and sign of cells found in the individual blob, based on the penetrations shown above. 


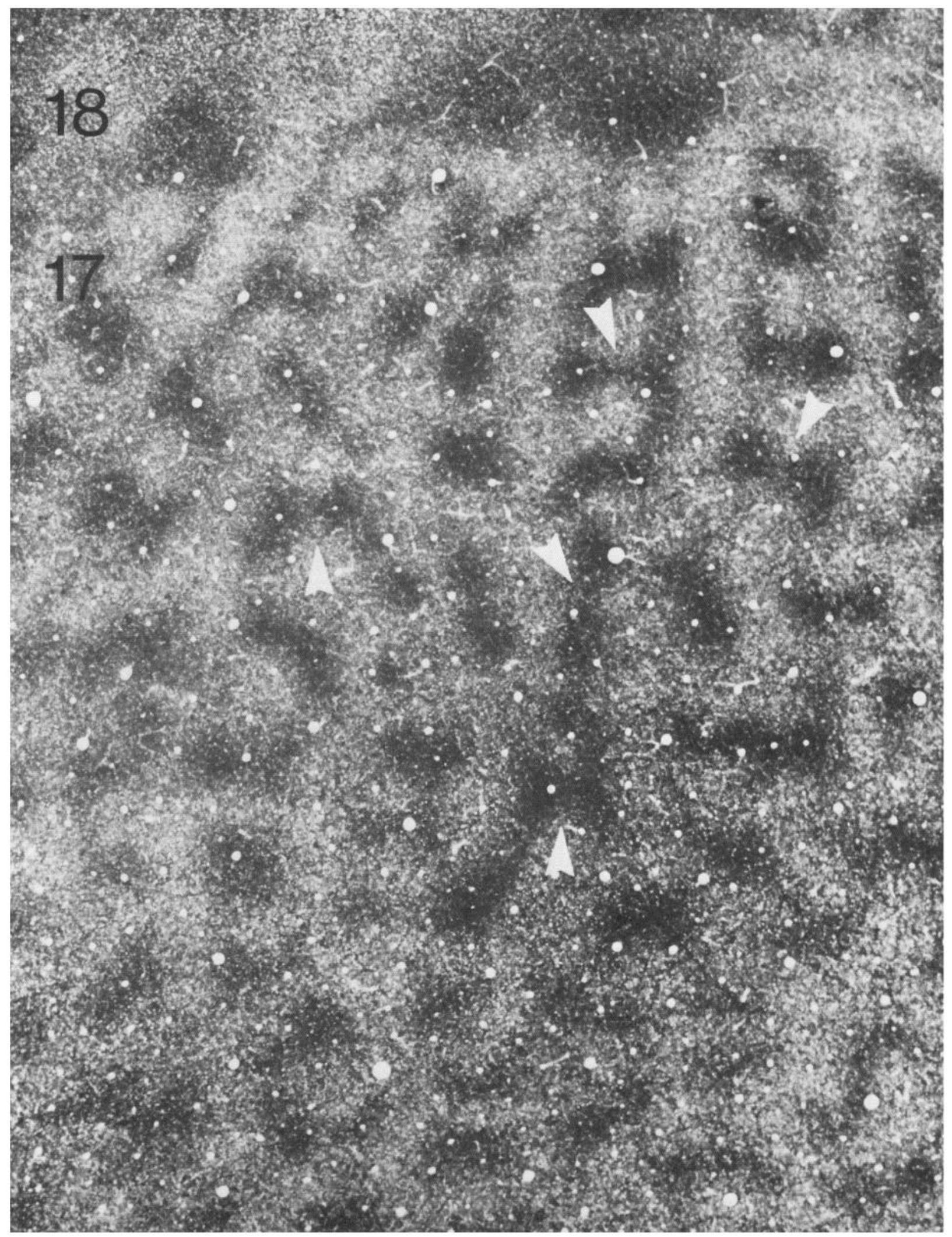

Figure 9. Photograph of section, stained for cytochrome oxidase, of monkey striate cortex, including the area 17/18 border. Note the bands of staining between individual blobs, both along the ocular dominance columns (perpendicular to the 17/18 border) as well as across ocular dominance columns. 


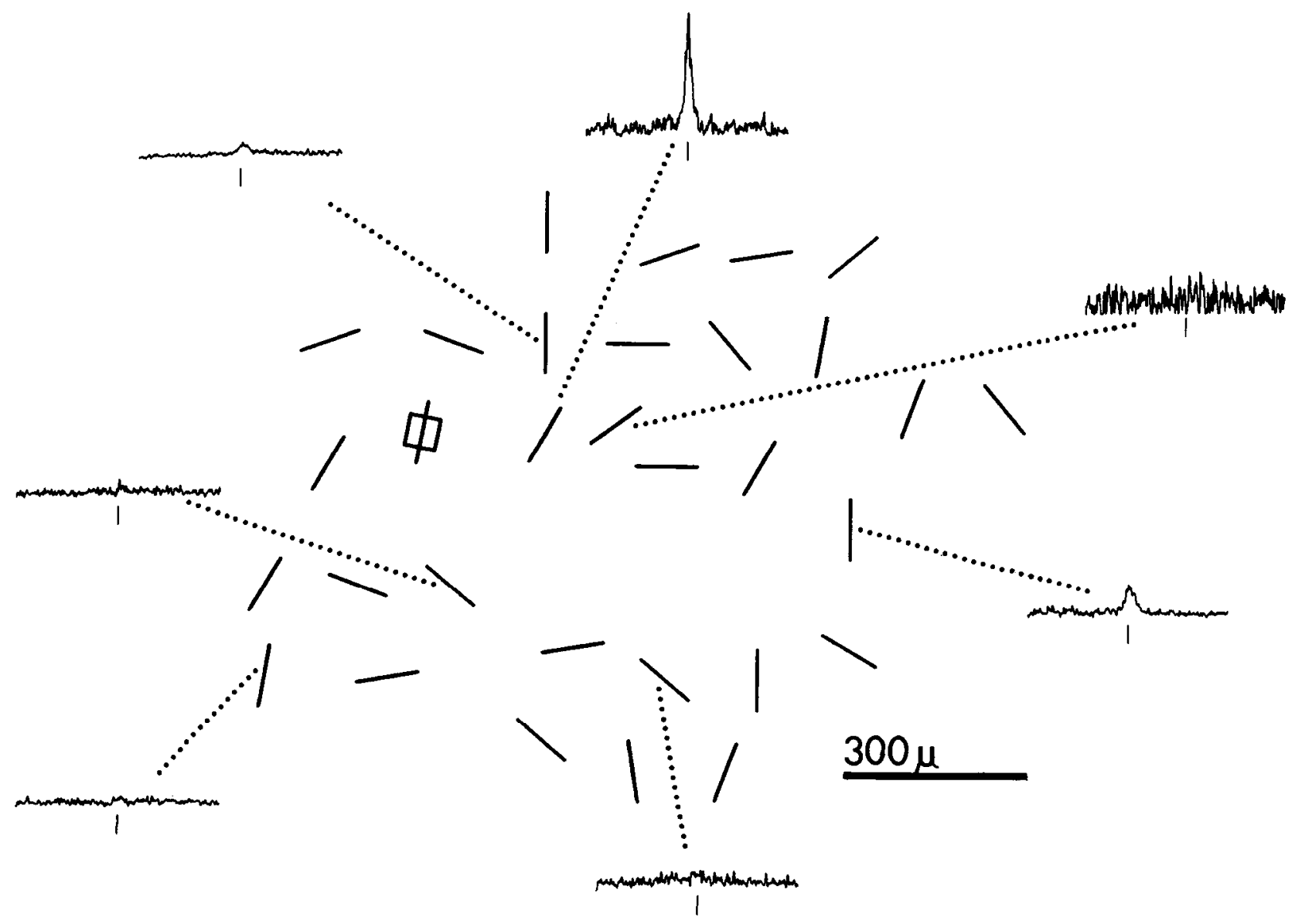

Figure 10. Cross-correlations between a reference site and selected test sites. Orientation map of a region of striate cortex derived from multiple electrode penetrations. The reference site had an orientation preference of $70^{\circ}$. Correlograms were normalized by the baseline correlation. Peaked correlograms, with varying electrode separations, occurred only if the test site's orientation preference was close to $70^{\circ}$. The recording site at the lower left corner had an ocular dominance different from the reference site.

columnar specificity, varying cortical distances, and among blob and interblob cells. The results from these studies are summarized in Table 2, and the different classes of interaction are discussed in detail below.

Horizontal interactions in interblob regions. Among the oriented cells in the interblob regions, peak correlograms were obtained only between cells with matched orientation preference. These peaked correlograms were positive and indicated common excitatory input, monosynaptic excitation, or both. To further examine the horizontal extent of these interactions, we mapped a portion of cortex using multiple vertical penetrations and determined the orientation preference and ocular dominance at each site. A single unit was then isolated at a chosen reference site and a series of cross-correlations was collected between this reference cell and cells located at the other test sites (Fig. 10). Among the various horizontal distances tested, peak correlograms were obtained only when the orientation preference of the test cell matched that of the reference cell. The strong dependence of correlated firing on matched orientation preference, and not just similar ocular dominance alone, leads us to believe that at least a majority of these interactions among interblob cells are due to connections intrinsic to the cortex and not due to common input from the LGN. As can be seen in Table 2. matched orientation preference and ocular dominance were both important factors related to the occurrence of correlated firing.
Horizontal interactions between blob and interblob regions. We also used cross-correlation to study the pattern of connections among blob and interblob cells. Figure 11 shows an example of a peaked cross-correlogram between 2 oriented interblob cells with matched orientation preference (cells A and B1). We then moved one of the electrodes and located a bloblike region with unoriented, monocular fields and isolated a Type III blob cell. The resultant cross-correlation was flat (cells $A$ and B2). We later confirmed the location of the Type III cell to be in a blob region through histological reconstruction. In this example, an oriented interblob cell showed interactions with another interblob cell with matched orientation preference but showed no interactions with a neighboring Type III blob ccll.

In another example (Fig. 12), we first recorded from 2 Type IV blob cells in different blobs and obtained a peaked correlogram. Moving one of the electrodes to an interblob region, we recorded from an oriented cell, and the resulting correlogram was flat. Thus, a Type IV blob cell exhibited correlated firing with another Type IV blob cell, but not a neighboring oriented interblob cell. These findings suggest that the connections between blob and blob regions are segregated from those between interblob and interblob regions. As summarized in Table 2, no interactions were found between non-color-selective interblob cells and blob cells in a sample of 32 correlograms.

An additional set of cross-correlations between color-selective oriented cells and color-selective blob cells revealed that only 

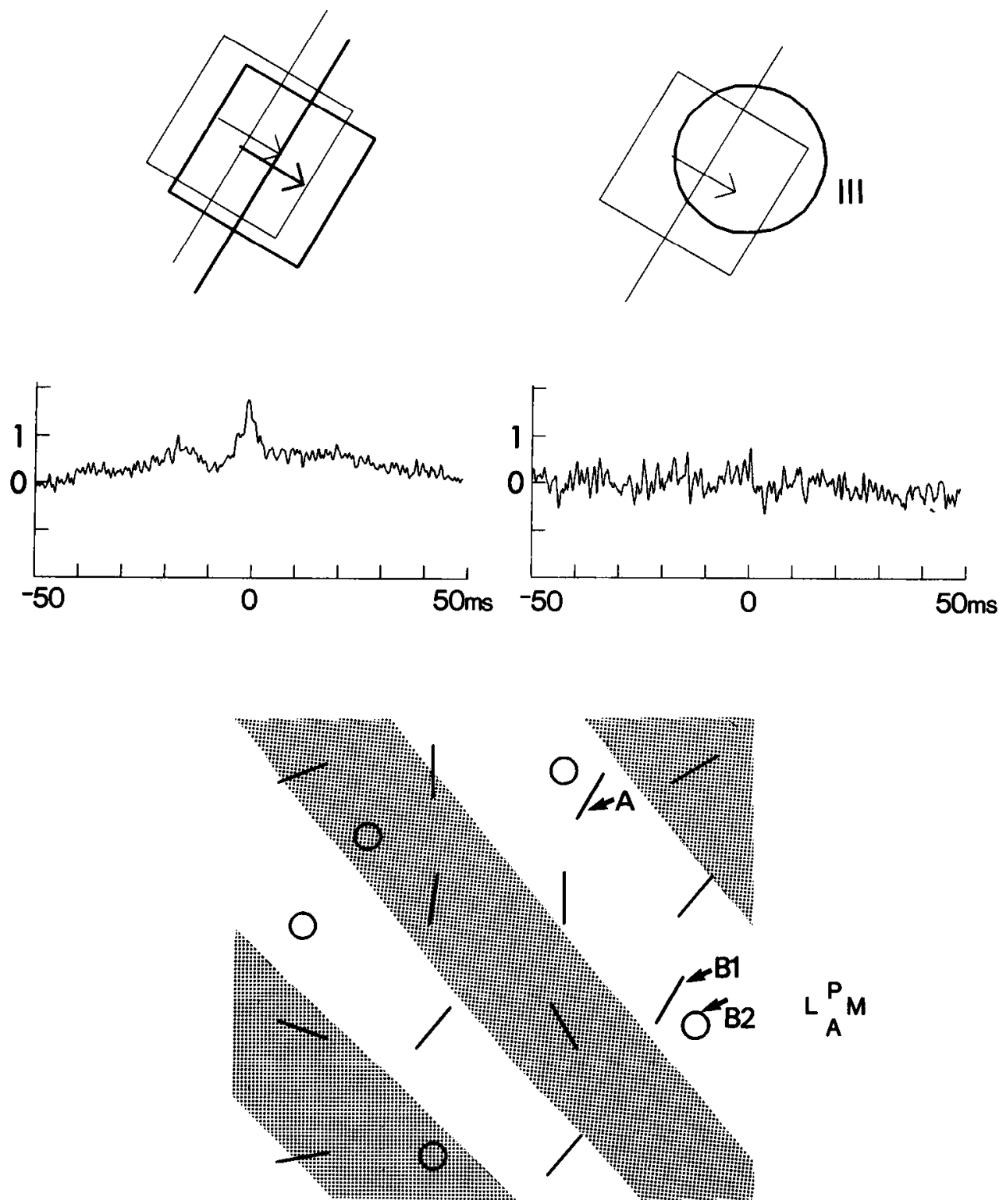

Figure 11. Top, Correlograms obtained from 2 cell pairs. Bottom, Functional map showing orientation preferences at several sites (black bars), ocular dominance columns derived from the recordings (stippled bands), and locations of several blob regions (open circles). First cell pair (left) were both oriented, interblob cells with similar receptive field properties: orientation preference of $60^{\circ}$, directional preference to the right, and ocular dominance of 3 . One electrode remained fixed at site $A$, while the second electrode moved from site $B 1$ to site $B 2$, in a blob region and isolated a Type III blob cell. The resultant correlogram is shown on the right. The correlograms were collected with a $\pm 50 \mathrm{msec}$ window, shuffle-corrected, low-pass-filtered, and normalized to baseline. Units on the ordinate refer to multiples of baseline correlation (see Ts'o et al., 1986).

when the color selectivity of the pair was matched did peaked correlograms occur. The blob cells that interacted with the orientation and color-selective complex cells had either Type I or modified Type II fields. We have not determined any general rule as to the location of the color-selective oriented cells in relation to the blob regions.

Interactions between blob regions. Our results show that blob cells tended to interact with other blob cells of the same receptive field type and color opponency. In one penetration (Fig. 13), we first recorded from a blue-On yellow-Off Type I cell and an Off center broadband Type III cell. We obtained a nearly flat correlogram, with perhaps a trace of inhibition. Moving one electrode, we then recorded from another Type I blob cell similar to the Type I cell at the other electrode-blue-On yellow-Offand obtained a correlogram with an excitatory monosynaptic pattern (asymmetric peak and shifted entirely to one side of the zero bin). This interaction represents a monosynaptic connection between Type I blue/yellow blob cells. While the reference electrode continued to record from one Type I blue/yellow cell, the second electrode was advanced further. Peaked correlograms were obtaned only when other Type I blue/yellow cells were encountered. The correlograms reflected both monosynaptic and common input interactions. Peaked correlograms were not found between $\mathrm{red} / g r e e n$ and blue/yellow color opponent cells. We observed this pattern of interaction both between pairs of cells in the same blob and in 2 different blobs.

Our results also contributed to understanding the connections underlying the generation of specific receptive field properties. For example, we wished to determine the sources of intrinsic input to the modified Type II cell. A cross-correlogram was obtained between a standard red-On, green-Off Type II and a red-On, grecn-Off modificd Typc II ccll (Fig. 14, left). The correlogram indicates an excitatory monosynaptic connection from the standard Type II to the modified Type II cell. Such connections may contribute to the construction of the modified Type II receptive field in the cortex. As mentioned above, we also found peaked correlograms between modified Type II cells and color-selective oriented complex cells with matching color 


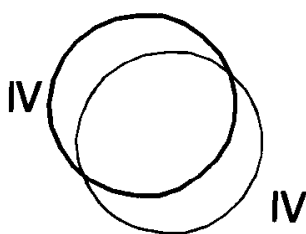

Figure 12. Correlograms from 2 cell pairs. First, 2 Type IV blob cells in different but adjacent blobs with matching ocular dominance (left). The circles represent the size of the center of the cells' receptive field $\left(0.7^{\circ}\right)$. One electrode was then moved to a neighboring interblob site and isolated an oriented, complex cell (correlogram on right).
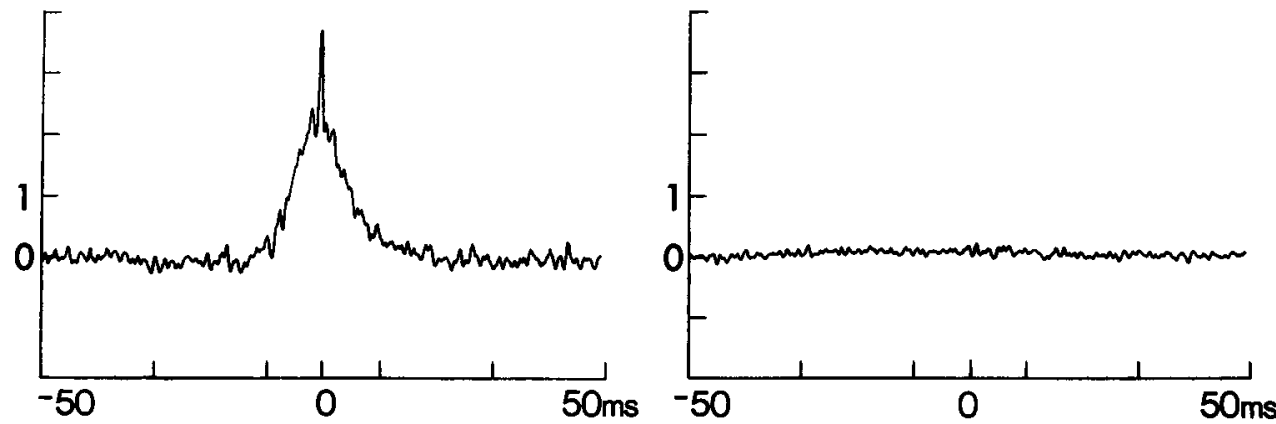

specificity (Fig. 14, right). In this example, the red-On greenOff modified Type II cell may have contributed to the green trailing edge response of the green-selective complex cell.

\section{Discussion}

Organization of color-selective cells. The organization of the visual cortex into clusters or columns of cells with similar receptive field properties had been established with the original description by Hubel and Wiesel (1962). Studies on the distribution of color-selective cells in the visual cortex by Gouras (1974) and Michael (1981) led to the suggestion that color preference is also arranged in a columnar fashion. A further advance in understanding the distribution of color-selective cells came with the discovery of cytochrome oxidase-rich blobs in the superficial layers of monkey striate cortex (Wong-Riley, 1979; Horton and Hubel, 1981). The blobs have a high proportion of cells that are color selective and are also unoriented and monocular (Livingstone and Hubel, 1984a). The results presented in the current study revealed that within the population of colorselective cells there is a subparcellation of function such that individual blobs specialize in one of the 2 color-opponency systems, either blue-yellow or red-green. Dow and Vautin (1987) have suggested a somewhat different organization of the colorselective cells, with centers of red or blue wavelength selectivity surrounded by regions sensitive to the middle wavelengths.

At the retinal eccentricity we examined, we found that the
1
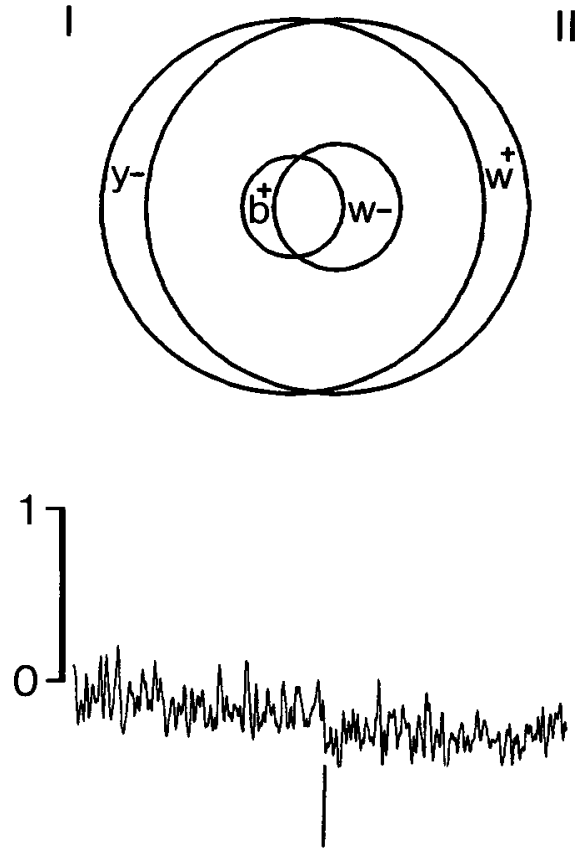

III

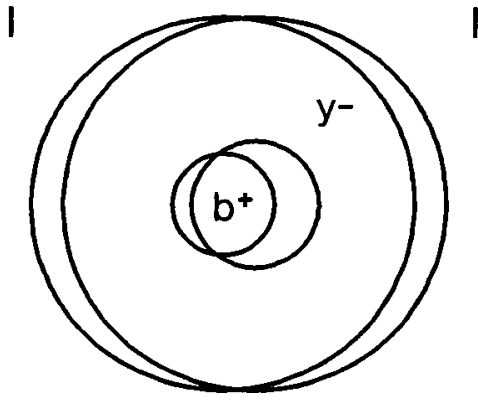

Figure 13. Left, Blue-On yellow-Off Type I to Type III Off-center correlogram. Right, Blue-On yellow-Off Type I to blue-On yellow-Off Type I cell. The shape and pattern of the peak indicates an excitatory monosynaptic connection from one Type I to the other: $N_{a}=4378$; $N_{b}=19,370$. Contribution, $13.2 \%$; effectiveness, $3.0 \%$. 


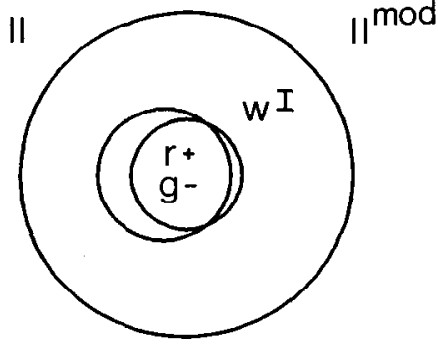

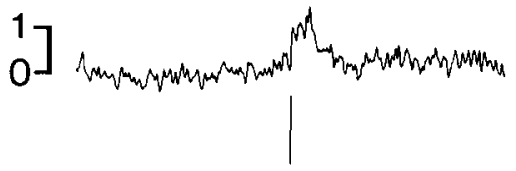
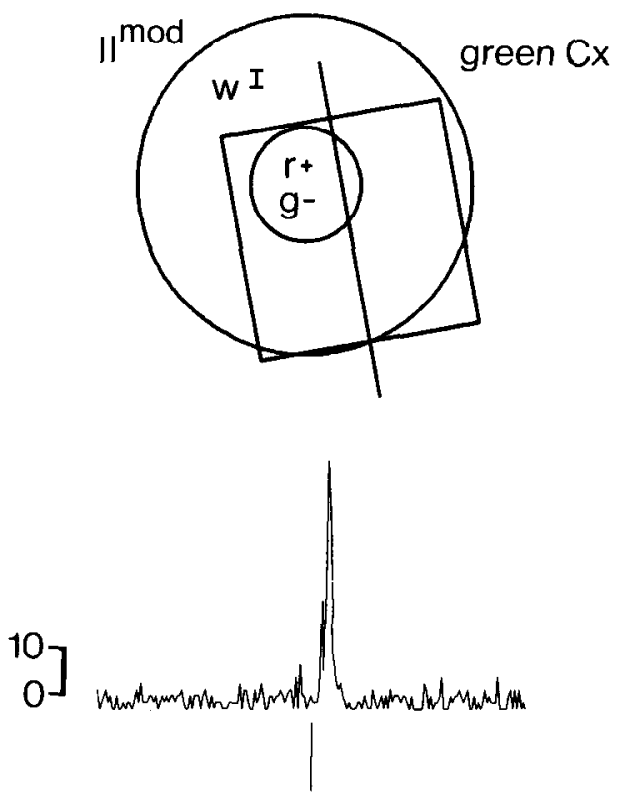

Figure 14. Left, Correlogram from a red-On green-Off Type II cell to a modified red-On green-Off Type II cell. The correlogram indicates an excitatory monosynaptic connection from the Type II to the modified Type II cell. Correlation window, $\pm 50 \mathrm{msec} ; N_{a}=$ $8988 ; N_{b}=28,610$; contribution, $1.3 \%$; effectiveness, $4 \%$. Right, Correlogram from a red-On green-Off modified Type II cell to an oriented, complex cell that preferred a green moving bar or edge stimulus. The correlogram indicates an excitatory monosynaptic connection from the modified Type II to the green complex cell. The correlogram is shown with a narrower correlation window $( \pm 5$ msec) and smaller scaling factor to display the peak in better detail: $N_{a}=1092$; $N_{b}=2080$; contribution, $11.7 \%$; effectiveness, $6.2 \%$. red/green blobs outnumbered the blue/yellow blobs by a ratio of 3:1. We could not discern any general pattern of the relative distribution of each type of blob but do not believe that our evidence supports the checkerboard model presented by Dow and Vautin (1987). Therc is evidence, however, that the bluc/ yellow blobs are often adjacent to other blue/yellow blobs, providing a clustered organization on a larger scale (for example, see Fig. 8). Further functional mapping over an even greater cortical area will be required to uncover any systematic arrangement of these 2 classes of blobs.

The proportions of the 2 types of blobs undoubtedly reflect the relative numbers of different types of color cells at antecedent stages of the visual pathway. For example, the blue/yellow retinal ganglion cells compose roughly $20 \%$ of the total, with $50 \%$ $\mathrm{red} /$ green and the remainder being broadband (Gouras, 1968; DeMonasterio and Gouras, 1975; Schiller and Malpeli, 1978). Cells in the LGN have been reported to be roughly $5 \%$ blue/ yellow versus 60\% red/green (Wiesel and Hubel, 1966; Dreher et al., 1976; Krüger, 1977). These proportions change with eccentricity. For example, in the photoreceptor layer there is a relative paucity of blue cones in the fovea $(<1 \%)$ versus the parafoveal representation (peaking at roughly $16 \%$; Sperling et al., 1980). From this distribution of blue cones, one would predict a different pattern of red/green versus blue/yellow specific blobs in different parts of the striate cortex. The relative sparcity of blue/yellow blobs raises the issue of the adequacy of visual field coverage in the blue/yellow system. To address this one would have to know more about the receptive field scatter within a blob and the average visual field spacing between the blue/ yellow blobs.

Is the color specificity of blobs maintained from the superficial layers to the deeper cortical layers? This question is important in considering the patterns of connectivity leading to the receptive field properties of blob cells. Though the interlaminar connections of cortex have not been studied in relation to the cytochrome oxidase blob system, in general, the superficial layers are known to receive substantial input from layer $4 \mathrm{Cb}$ (Lund and Boothe, 1975). Our finding that cells in layer $4 \mathrm{C}$ had iden-
Table 2. Property dependence of correlograms

\begin{tabular}{lclll}
$\begin{array}{l}\text { Interblob } \\
\text { cells }\end{array}$ & $\begin{array}{l}\text { Peaked } \\
(\%)\end{array}$ & $\begin{array}{l}\text { Not } \\
\text { peaked } \\
(\%)\end{array}$ & $\begin{array}{l}\text { Sample } \\
\text { size }\end{array}$ & Significance \\
\hline $\begin{array}{l}\text { Orientation } \\
\quad \text { Similar }\end{array}$ & 77 & 23 & 82 & \\
$\quad \begin{array}{l}\text { Different } \\
\text { Ocular dominance }\end{array}$ & 3 & 97 & 36 & $p \ll 0.005$ \\
$\quad$ Similar & 66 & 34 & 97 & $p \ll 0.005$ \\
$\quad$ Different & 5 & 95 & 21 &
\end{tabular}

Blob cells

\begin{tabular}{lcrcc}
\hline Ocular dominance & & & & \\
Similar & 58 & 41 & 51 & $p \ll 0.005$ \\
Different & 0 & 100 & 48 & \\
RF type and color opponency & & & \\
Similar & 76 & 24 & 36 & $p \ll 0.005$ \\
Different & 10 & 90 & 63 & \\
Interblob cells vs blob cells & & & \\
\hline \multicolumn{5}{r}{} \\
Color oriented vs blob cells & 100 & 32 & \\
Color selectivity & & & & \\
Similar & 100 & 0 & 8 & \\
Different & 0 & 100 & 3
\end{tabular}

Relationship between receptive field properties and peaked correlograms Determination of "peaked" and "not peaked" was performed by a computer program that calculated the strength of any interactions and grouped each correlogram into 1 of 4 strength groups (see Ts'o et al., 1986). Correlograms in strength groups 2 and 3 were marked "peaked," and correlograms in groups 0 and 1 were counted as "not peaked." Orientation of pairs of interblob cells was considered similar if they differed by $30^{\circ}$ or less. The ocular dominance of pairs of cells was considered similar if the difference in group ranking was 2 or less [of possible groups $1(100 \%$ contralateral) to $7(100 \%$ ipsilateral)]. The receptive field types of pairs of blob cells were classed as "same" if the chromatic and spatial classifications (Types I, II, mod II, III, IV) were identical, and the color opponency and sign (On vs Off spatial organization) were identical. Significance level was computed with a $x^{2}$ contingency test. 
tical color specificity to the cells in the overlying blobs is consistent with the projection from layer $4 \mathrm{C}$ to layer 3 . In addition to their input from layer 4 , blob cells receive a direct projection from the interlaminar layers of the LGN (Fitzpatrick et al., 1983). The properties of the cells within the interlaminar layers have not been described, and the relative roles of the direct thalamic and layer $4 \mathrm{C}$ input to the blobs are not yet understood.

Though the correspondence of the color-opponency type between layer $2+3$ and layer $4 \mathrm{C}$ supports the notion of a color column, it is not known whether the cells underneath the blobs in layers 5 and 6 share the color properties of the blobs. Moreover, the existence of many oriented, directional cells in layer $4 \mathrm{~B}$ under blobs sccms to be in violation of the notion of a color column as classically defined. However, in a few penetrations we found unoriented color-specific cells along the entire course from the superficial layers to layer $4 \mathrm{C}$. One possible interpretation of this result is that the color "column," rather than being a cylindrical structure, is thinner in the portion that passes through layer 4B.

In considering the functional architecture of color, an outstanding question is the placement of the color-specific oriented cells relative to the blobs. We found occasional oriented colorspecific cells in our penetrations into blob regions, and also at sites close to blobs. These findings are consistent with a localization of the oriented color cells in a "periblob" distribution, but the evidence is still only suggestive.

Receptive field properties of blob cells. Though the functional architecture of the color system is an important element in understanding how the cortex analyzes visual information, the main thrust of our work has been to understand how the functional properties of cells are transformed at progressive stages along the visual pathway and to understand the mechanism of this transformation at the level of connectivity. Our findings concerning the receptive field properties of blob cells provide some insight into this transformation within the submodality of color. The principal difference that we found between receptive fields of LGN cells and those of blob cells was seen in the modified Type II cell. These cells combine color opponency in the center with broadband spatial opponency and thus may provide an integration of information concerning color contrast with information concerning luminance contrast or spatial positioning. Since standard Type II cells have relatively larger receptive fields without surround suppression, they would give poor spatial resolution. The surround suppression exhibited by the modified Type II seems similar to other surround suppression, such as that of the Type III cells, except that the antagonism is both to the On and Off responses in the center.

We found very few true double-opponent cells in the blob regions. The similarities between our modified Type II cells and double-opponent cells suggests that the modified Type II cells may have been mistaken for double-opponent cells in other studies. For example, both show opponent color responses to small spots and are suppressed by large spots of any color. However, the modified Type II cell, unlike a true double-opponent cell, does not respond well to isoluminant color contrast and, in the surround, does not exhibit opponent color responses of opposite sign from those of the center (Daw, 1968). Since occurrence of true double-opponent cells seems quite rare and the stimulus used in earlier studies could not distinguish the double-opponent from modified Type II cells, and because of the significant functional difference between the 2 types, we believe the modified Type II classification is more appropriate.
We found other differences between the color cells of the LGN and the blob cells. One finding was that the percentage of blue/ yellow opponent cells relative to red/green opponent cells was higher in the cortex than that reported for the LGN. Moreover, among the population of blue/yellow opponent cells we found a higher proportion of yellow-On blue-Off cells than seen in the LGN (see above). Another difference was that the sign of the tonic red surround of Type IV cells in the blobs was usually excitatory rather than inhibitory as in the LGN (Wiesel and Hubel, 1966).

Connectivity among blob and interblob regions. Our crosscorrelation studies uncovered excitatory monosynaptic connections from standard Typc II to modificd Type II cells. These connections may contribute to the construction of the modified Type II receptive field in the cortex. One possible scheme uses a standard Type II field to provide the center response and derive the surround antagonism from the summing inputs from Type I, Type II, or Type III cells or a mixture of cells of each type, having suitably positioned fields. Such models, however, at least in their simplest form are not entirely satisfactory, since they do not adequately explain the properties of the surround antagonism of the modified Type II cell.

Our findings, using cross-correlation analysis, of correlated firing between pairs of oriented, interblob cells with matched orientation preference are similar to those we reported for the cat striate cortex (Ts'o et al., 1986). As in the cat, excitatory correlograms were obtained over a range of horizontal distances, suggesting a correspondence to the anatomically demonstrated clustered long-range horizontal connections. Since these interactions were dependent on matched orientation preference and not to matched eye preference alone. it is likely that the underlying connections are intrinsic to the cortex and are not due to common input from the LGN.

Like the specificity of the interblob connections for columns of matched orientation preference, among the blob connections we found a specificity of blob connections for receptive field type (e.g., I, II, or III) and color selectivity. Interactions between blob cells both within a single blob and between 2 different blobs were observed. We obtained both common input and monosynaptic excitatory correlograms. While the monosynaptic excitatory correlograms are probably due to intrinsic connections in the cortex, it is less easy to be certain of the source of the common input correlograms. It is possible that a portion of the interactions between 2 blob cells with similar receptive field properties is due to shared input arising from either layer $4 \mathrm{C}$ or the LGN. Further studies are required to sort out this issue.

No interactions between blob cells and the oriented broadband interblob cells were found. The segregation of connections between blob/blob and interblob/interblob may correspond to the anatomical demonstration of a similar segregation shown by focal extracellular injections of HRP (Livingstone and Hubel, 1984b). Though this segregation of connections, taken together with the partitioning of color-specific unoriented cells into the blobs, supports the idea of a separation of form and color into different cell populations, the existence of color-specific oriented cells is indicative of a convergence of form and color information at the single cell level. Direct demonstration of interactions contributing to this convergence comes from our finding of peaked correlograms between color-selective unoriented and color-selective complex cells. These interactions represent further evidence that color and form are not necessarily segregated. While the anatomical substrate of such interactions is not known, 
one possibility is that there exist connections between blob and interblob cells that were not visible in the studies using extracellular HRP injection.

Our studies have revealed specific functional connections that extend horizontally among oriented cells and among color-selective cells. It is possible that various classes of horizontal connections subserve different functions. We suggest that closerrange connections, including some found between blob cells, may be involved with the building of new receptive field types, such as the modified Type II and color-selective oriented cells. On the other hand, the long-range horizontal connections between cells of like functional properties may contribute to subthreshold effects or other receptive field properties not revealed by classicial receptive field analysis (Allman et al., 1985). These properties may require visual information integrated over a large area of the visual field and thus allow a cell's responses to be modulated by context.

\section{References}

Allman, J., F. Miezin, and E. McGuinness (1985) Stimulus specific responses from beyond the classical receptive field: Neurophysiological mechanisms for local-global comparisons in visual neurons. Annu. Rev. Neurosci. 8: 407-430.

Daw, N. W. (1968) Colour-coded ganglion cells in the goldfish retina: Extension of their receptive fields by means of new stimuli. J. Physiol. (Lond.) 197: 567-592.

DeMonasterio, F. M., and P. Gouras (1975) Functional properties of ganglion cells of the rhesus monkey retina. J. Physiol. (Lond.) 251: $167-196$.

Dow, B. M., and R. G. Vautin (1987) Horizontal segregation of color information in the middle layers of foveal striate cortex. J. Neurophysiol. 57: 712-739.

Dreher, B., Y. Fukada, and R. Rodieck (1976) Identification, classification and anatomical segregation of cells with $\mathrm{X}$-like and $\mathrm{Y}$-like properties in the lateral geniculate nucleus of old-world primates. J. Physiol. (Lond.) 258: 433-452.

Fisken, R. A., L. J. Garey, and T. P. S. Powell (1975) The intrinsic, association and commissural connections of area 17 of the visual cortex. Phil. Trans. R. Soc. London 272: 487-536.

Fitzpatrick, D., K. Itoh, and I. T. Diamond (1983) The laminar organization of the lateral geniculate body and the striate cortex in the squirrel monkey (Saimiri sciureus). J. Neurosci. 3: 673-702.

Fitzpatrick D., J. S. Lund, and G. G. Blasdel (1985) Intrinsic connections of Macaque striate cortex: Afferent and efferent connections of layer 4C. J. Neurosci. 5: 3329-3349.

Gilbert, C. D., and T. N. Wiesel (1979) Morphology and intracortical projections of functionally identified neurons in cat visual cortex. Nature 280: $120-125$.

Gilbert, C. D., and T. N. Wiesel (1983) Clustered intrinsic connections in cat visual cortex. J. Neurosci. 3: 1116-1133.

Gouras, P. (1968) Identification of cone mechanisms in monkey ganglion cells. J. Physiol. (Lond.) 199: 533-547.

Gouras, P. (1974) Opponent-colour cells in different layers of foveal striate cortex. J. Physiol. (Lond.) 238: 583-602.

Horton, J. C. (1984) Cytochrome oxidase patches: a new cytoarchi- tectonic feature of monkey visual cortex. Phil. Trans. R. Soc. London 304: 199-253.

Horton, J. C., and D. H. Hubel (1981) A regular patchy distribution of cytochrome-oxidase staining in primary visual cortex of the macaque monkey. Nature 292: 762-764.

Hubel, D. H. (1957) Tungsten microelectrodes for recording from single units. Science 125: 549-550.

Hubel, D. H., and T. N. Wiesel (1962) Receptive fields, binocular interaction and functional architecture in the cat's visual cortex. J. Physiol. (Lond.) 160: 106-154.

Humphrey, A. L., and A. E. Hendrickson (1983) Background and stimulus-induced patterns of high metabolic activity in the visual cortex (area 17) of the squirrel and macaque monkey. J. Neurosci. 3: 345-358.

Krüger, J. (1977) Stimulus dependent colour specificity of monkey lateral geniculate neurones. Exp. Brain Res. 30: 297-311.

Levick, W. R., B. G. Cleland, and M. W. Dubin (1972) Lateral geniculate neurons of cat: Retinal inputs and physiology. Invest. Ophthalmol. 11: 302-311.

Livingstone, M. S., and D. H. Hubel (1984a) Anatomy and physiology of a color system in the primate visual cortex. J. Neurosci. 4: 309356.

Livingstone, M. S., and D. H. Hubel (1984b) Specificity of intrinsic connections in primate primary visual cortex. J. Neurosci. 4: 28302835.

Lorente de No, R. (1933) Studies on the structure of the cerebral cortex. J. Psychol. Neurol. 45: 382-438.

Lund, J. S., and R. G. Boothe (1975) Interlaminar connections and pyramidal neuron organization of the visual cortex, area 17 , of the Macaque monkey. J. Comp. Neurol. 159: 305-344.

Martin, K. A. C., and D. Whitteridge (1984) Form, function and intracortical projections of spiny neurones in the striate visual cortex of the cat. J. Physiol. (Lond.) 353: 463-504.

McGuire, B. A., C. D. Gilbert, and T. N. Wiesel (1985) Ultrastructural characterization of long-range clustered horizontal connections in monkey striate cortex. Soc. Neurosci. Abstr. 11: 11 .

Michael, C. R. (1981) Columnar organization of color cells in monkey's striate cortex. J. Neurophysiol. 46: 587-604.

Michael, C. R. (1985) Laminar segregation of color cells in the monkey's striate cortex. Vision Res. 25: 415-423.

Michael, C. R. (1986) Functional and morphological identification of double and single opponent color cells in layer IVCb of the monkey's striate cortex. Soc. Neurosci. Abstr. 12: 1497.

Rockland, K. S., and J. S. Lund (1982) Widespread periodic intrinsic connections in the tree shrew visual cortex. Science $215: 1532-1534$.

Schiller, P. H., and J. G. Malpeli (1978) Functional specificity of lateral geniculate nucleus laminae of the rhesus monkey. J. Neurophysiol. 41: 788-797.

Sperling. H. G., C. Johnson, and R. S. Harweth (1980) Differential spectral photic damage to primate cones. Vision Res. 20:1117.

Ts'o, D. Y., C. D. Gilbert, and T. N. Wiesel (1986) Relationships between horizontal interactions and functional architecture in cat striate cortex as revealed by cross-correlation analysis. J. Neurosci. 6: $1160-1170$.

Wiesel, T. N., and D. H. Hubel (1966) Spatial and chromatic interactions in the lateral geniculate body of the rhesus monkey. J. Neurophysiol. 29: 1115-1156.

Wong-Riley, M. T. T. (1979) Changes in the visual system of monocularly sutured or enucleated cats demonstrable with cytochrome oxidase histochemistry. Brain Res. 171: 11-28. 